University of Windsor

Scholarship at UWindsor

\title{
Variation in Plasma Corticosterone in Migratory Songbirds: A Test of the Migration-Modulation Hypothesis
}

\author{
Dominique N. Wagner \\ University of Windsor \\ David J. Green \\ University of Windsor \\ John . M. Cooper \\ University of Windsor \\ Oliver P. Love \\ University of Windsor \\ Tony D. Williams \\ University of Windsor
}

Follow this and additional works at: https://scholar.uwindsor.ca/biologypub

Part of the Biology Commons

\section{Recommended Citation}

Wagner, Dominique N.; Green, David J.; Cooper, John . M.; Love, Oliver P.; and Williams, Tony D., "Variation in Plasma Corticosterone in Migratory Songbirds: A Test of the Migration-Modulation Hypothesis" (2014). Physiological \& Biochemical Zoology, 87, 5, 695-703.

https://scholar.uwindsor.ca/biologypub/1163

This Article is brought to you for free and open access by the Department of Biological Sciences at Scholarship at UWindsor. It has been accepted for inclusion in Biological Sciences Publications by an authorized administrator of Scholarship at UWindsor. For more information, please contact scholarship@uwindsor.ca. 


\section{Variation in Plasma Corticosterone in Migratory Songbirds: A Test of the Migration-Modulation Hypothesis}

\author{
Dominique N. Wagner ${ }^{1, *}$ \\ David J. Green ${ }^{1}$ \\ John M. Cooper ${ }^{2}$ \\ Oliver P. Love ${ }^{3}$ \\ Tony D. Williams ${ }^{1}$ \\ ${ }^{1}$ Department of Biological Sciences, Simon Fraser University, \\ 8888 University Drive, Burnaby, British Columbia V5A 1S6, \\ Canada; ${ }^{2}$ Cooper, Beauchesne, and Associates, Box 646, 1799 \\ Swayne Road, Errington, British Columbia V0R 1V0, \\ Canada; ${ }^{3}$ Biological Sciences Department, University of \\ Windsor, Windsor, Ontario N9B 3P4, Canada
}

Accepted 4/7/2014; Electronically Published 8/14/2014

\begin{abstract}
Physiological mechanisms underlying migration remain poorly understood, but recent attention has focused on the role of the glucocorticoid hormone corticosterone (CORT) as a key endocrine regulator of migration. The migrationmodulation hypothesis ( $\mathrm{MMH}$ ) proposes that baseline plasma CORT levels are elevated in migratory birds to facilitate hyperphagia and lipogenesis and that further elevation of CORT in response to acute stress is suppressed. Consequently, CORT may be a poor indicator of individual condition or environmental variation in migratory birds. We tested the MMH by measuring baseline and stress-induced CORT in common yellowthroats (Geothlypis trichas) during fall migration over 2 consecutive years in the Revelstoke Reach drawdown zone, a migratory stopover site affected by local hydroelectric operations. Birds had low baseline CORT at initial capture $(<5 \mathrm{ng} / \mathrm{mL})$ and then showed a robust stress response, with CORT increasing to ca. $50 \mathrm{ng} /$ $\mathrm{mL}$ within 10-20 min. Our data therefore do not support the MMH. Baseline CORT did not vary with body mass, time of capture, Julian day, or year, suggesting that variable flooding regimes did not affect baseline CORT. Individual variation in the rate of increase in CORT was correlated with Julian day, being higher later in the migration period. Our data suggest that plasma CORT can be a useful metric in migration studies.
\end{abstract}

\footnotetext{
${ }^{\star}$ Corresponding author. Present address: Rosenstiel School of Marine and Atmospheric Science, University of Miami, 4600 Rickenbacker Causeway, Miami, Florida 33149; e-mail: dwagner@rsmas.miami.edu, dnw1@sfu.ca.

Physiological and Biochemical Zoology 87(5):695-703. 2014. (C) 2014 by The University of Chicago. All rights reserved. 1522-2152/2014/8705-3101\$15.00. DOI: $10.1086 / 676937$
}

\section{Introduction}

Migration between breeding and nonbreeding/wintering areas is a critically important event during the life cycle of many species (Ramenofsky and Wingfield 2007; Bowlin et al. 2010). However, the physiological mechanisms that trigger, maintain, and mediate the transition between stages (e.g., from reproduction to migration or vice versa) remain poorly understood. Although autumn (southward) migration in temperate birds takes a relatively short amount of time in an individual's life, it involves a complex series of events often including a postbreeding refractory period and prebasic molt and can potentially have important carryover effects that can be almost impossible to quantify at the migratory endpoints (Lobato et al. 2010; Sheehy et al. 2010; Pasinelli et al. 2011; Cornelius et al. 2013). For example, long-distance migratory shorebirds are very reliant on specific stopover sites for refueling along their migration routes, and a change in conditions at these stopover sites can have significant impacts on the overall migratory success (Baker et al. 2004; Kraan et al. 2010). Since many migratory species cover vast distances and will encounter several habitats of varying type and quality at different stopover sites during their migration, it has been difficult to assess how each habitat, or stopover site, may impact the physiology of the organism and ultimately the success of that individual's overall migration (Faaborg et al. 2010a, 2010b). Since the population of a migrant at a particular stopover site may change significantly from day to day during the course of a migration season (Seewagen et al. 2010), a physiological approach to assessment of habitat quality, or assessment of the quality of individual birds using specific stopover sites, might be able to provide additional insights beyond those usually derived from demographic methodologies (Williams et al. 2007). This physiological approach should allow for a more precise association between immediate environmental conditions and potential impacts they may have on individuals currently in that environment.

Although the physiological mechanisms underlying migration remain poorly understood, recent attention has focused on the role of the glucocorticoid hormone corticosterone (CORT) as a key endocrine regulator of migration (Ramenofsky and Wingfield 2007; Bowlin et al. 2010) and a potential tool for physiological assessment of condition in relation to environmental stress (Walker et al. 2005; Bonier et al. 2009a, 2009b). CORT is the main glucocorticoid responsible for regulation of metabolic homeostasis, fuel use, immune function, and the 
generalized stress response in amphibian, reptile, rodent, and avian species (Harvey et al. 1984; Romero 2004). It is both baseline variation and the capacity for CORT levels to change rapidly in response to a stressful event or environment that make measures of CORT of particular interest to conservation physiologists (Romero et al. 1997). For example, it has been suggested that variation in how plasma CORT concentration changes over time in response to a stressful event (e.g., being caught in a mist net, predator attack, or being flushed from cover), as well as variation in baseline levels, might provide reliable indicators of environmental stress (Wingfield et al. 1982; Marra and Holberton 1998; Kitaysky et al. 1999, 2001; 2007; Suorsa et al. 2003; Madliger and Love 2014). Similar techniques have been used successfully in crude oil-exposed marine iguanas (Amblyrhynchus cristatus) to assess how pollution affects survivorship (Romero and Wikelski 2002; Wikelski et al. 2002) and in spotted owl (Strix occidentalis) conservation work where fecal CORT concentration is measured as a metric of proximity of forestry activity (Wasser and Hunt 2005) without having to actively disturb the study species. Nevertheless, the functional role that CORT plays in regulating migration-related changes in behavior and physiology is not yet well understood (Holberton et al. 2007), and CORT levels must be interpreted in both life-history and environmentally dependent manners to be relevant conservation biomarkers (Madliger and Love 2014).

Here we investigate sources of variation in plasma baseline and stress-induced CORT in Neotropical songbirds at a migratory stopover site to test the migration-modulation hypothesis (MMH; Holberton et al. 1996). This hypothesis suggested that migratory Neotropical passerines should not exhibit a typical stress response to capture and handling and predicted that (1) baseline CORT should be elevated throughout the migratory period (cf. Romero 2002) to facilitate hyperphagia and lipogenesis, independent of short-term changes in energetic condition, and (2) further elevation of CORT in response to acute stress is suppressed during migration to protect skeletal muscle needed for flight from the catabolic effects of elevated plasma CORT (Holberton et al. 1996; Holberton 1999; Long and Holberton 2004; Raja-aho et al. 2010). In contrast, a review by Romero (2002) suggested that both baseline and stressinduced plasma CORT levels might be relatively low during autumn migration compared to other phases of the annual cycle, including spring migration (Romero 2002). Our study was conducted in the broader context of validating physiological (hormonal and plasma metabolite) approaches to assessment of habitat quality in relation to migration and reservoir water management (Wagner 2012), and we interpret our results in this context. Clearly, determining how baseline and stressinduced CORT are modulated during migration will improve the ability to determine whether this biomarker can be used to assess both the underlying regulatory mechanisms of migration and its potential synergistic effects with environmental stressors. In this study we tested the MMH by measuring baseline and maximum stress-induced CORT levels over 2 consecutive years, using a standardized handling protocol, in common yellowthroats (Geothlypis trichas) during autumn migration at the Columbia River-Revelstoke Migration Monitoring Station in British Columbia, Canada. The aims of this study were (1) to measure variation in baseline levels of CORT in migrating passerines in relation to age, sex, body mass, and date or timing of autumn migration and (2) to test the $\mathrm{MMH}$ in the context of whether plasma CORT concentrations can provide a useful monitoring tool in migration studies by evaluating changes in CORT in two years with very different water levels (as a potential environmental stressor).

\section{Material and Methods}

\section{Study Species and Study Site}

Fieldwork for this study was conducted at the Columbia RiverRevelstoke Migration Monitoring Station on Machete Island, $\sim 2 \mathrm{~km}$ south of Revelstoke, British Columbia, Canada $\left(50^{\circ} 58^{\prime} 13.29^{\prime \prime} \mathrm{N}, 118^{\circ} 11^{\prime} 56.14^{\prime \prime} \mathrm{W}\right)$ during fall migration in 2008 and 2009. Machete Island is a semiwooded riparian habitat of about 30 ha, located in the drawdown zone of Arrow Lakes Reservoir. Machete Island is composed of deciduous forest, dominated by cottonwood (Populus sp.) with a diverse understory surrounded by willow scrub (Green et al. 2011). Water levels in the drawdown zone fluctuate throughout both the migratory period, being highest at the beginning of the migration season and lowest near the end, and across years (fig. 1). Higher water levels reduce the habitat available to migrants during stopover and may increase competition in the remaining habitat (Green et al. 2011), thereby potentially impacting baseline and stress-induced plasma CORT levels, an indicator of individual health and condition (Walker et al. 2005; Bonier et al. 2009a, 2009b).

\section{Capture and Blood Sampling}

We captured and blood sampled common yellowthroats in 2008 ( $n=13)$ and $2009(n=37)$ using two constantly monitored passive mist nets (Angelier et al. 2010) located approximately $150 \mathrm{~m}$ from the migration monitoring mist nets. Nets were opened $30 \mathrm{~min}$ after dawn and monitored for $4-5 \mathrm{~h}$ a day for $18 \mathrm{~d}$ between August 1 and September 30 in 2008 and $34 \mathrm{~d}$ for the same period in 2009. This monitoring occurred during the known migration period of this species (Pyle 1997; Sauer et al. 2011). Upon capture, birds were extracted and blood was sampled within 3 min to obtain a baseline measure of CORT (Wingfield et al. 1982; Romero and Reed 2005). Birds were sampled from the left brachial artery with a 26-gauge needle, and blood (50-100 $\mu \mathrm{L})$ was collected into heparinized microcapillary tubes. We employed standard procedures for measuring stress-induced or maximum plasma CORT levels, which involve blood sampling birds at $<3 \mathrm{~min}$, placing birds in a cloth bag to stimulate a standardized stress response (Wingfield et al. 1992; Holberton et al. 1996; Angelier et al. 2010), and then obtaining a second blood sample after $30 \mathrm{~min}$. Since we also wished to validate the time course of stress-induced changes in plasma CORT in these small-bodied migrants, we also sam- 


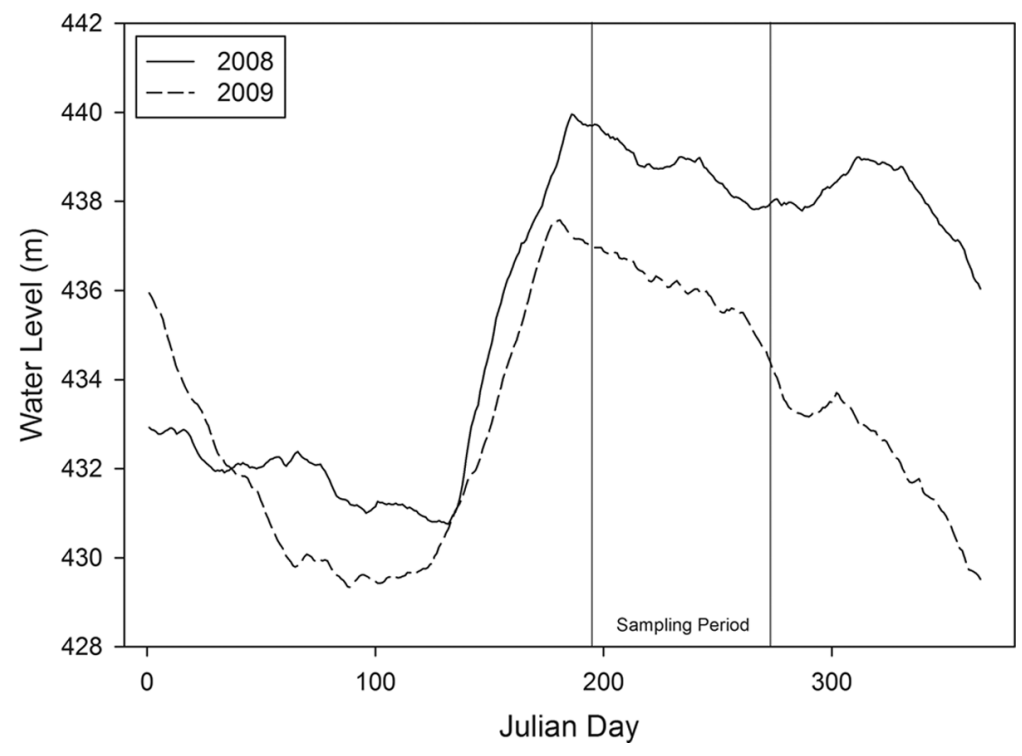

Figure 1. Variation in water levels of Revelstoke Reach, British Columbia, in 2008 and 2009. Revelstoke Reach is a migratory stopover site used by the common yellowthroat.

pled birds after 10,20 , or $30 \min (2008, n=3,3$, and 7 , respectively; $2009, n=13,10$, and 14 , respectively; time allocated sequentially by capture order), for a maximum of two samples from each individual (not all individuals were able to be sampled twice). Sampled individuals showed no signs of molt or accumulated fat. After blood sampling was complete, birds were identified to age and sex (Pyle 1997), measured (body mass, tarsus length, wing cord length, fat, and molt score), banded with aluminum US Fish and Wildlife Service bands, and released.

\section{Hormone Assay}

Blood samples were stored at $4^{\circ} \mathrm{C}$ for up to $4 \mathrm{~h}$ before being centrifuged for $6 \mathrm{~min}$ at 10,000 $\mathrm{g}$ when plasma was collected and then stored at $-20^{\circ} \mathrm{C}$ until assayed. A previously validated commercially available CORT enzyme-linked immunosorbent assay (Assay Designs, Ann Arbor, MI; catalog no. 901-097) was used to determine concentration of CORT hormone (Breuner and Orchinik 2002; Love et al. 2004, 2005; Love and Williams 2008). Prior to assaying individual samples, an optimization protocol was conducted to determine optimal dilution and necessity for plasma extraction. A plasma pool was created from five individuals, and both dichloromethane-extracted and nonextracted (raw) plasma pools were assayed at three dilutions to confirm linearity with the assay's standard curve and to detect the optimal dilution. Extraction did not increase our ability to determine either baseline or stress-induced CORT levels, and as such we used nonextracted samples for individual analyses. Assays were run at a total volume of $100 \mu \mathrm{L}$ with a $1: 30,1: 40$, or $1: 80$ dilution (depending on available plasma volume) and a $1.5 \%$ steroid displacement buffer. Following kit instructions, we incubated samples at $26^{\circ} \mathrm{C}$ under shaking at
$5,000 \mathrm{rpm}$ for $2 \mathrm{~h}$ and then incubated them at $26^{\circ} \mathrm{C}$ a further $1 \mathrm{~h}$ without shaking. Samples were run in triplicate across two plates in 2008, with intra- and interassay coefficient of variation being $4.9 \%$ and $5.4 \%$, respectively, and five plates in 2009 with intra- and interassay coefficient of variation being $2.3 \%$ and $9.6 \%$, respectively. Mean values for CORT at each time point were used to develop a stress response curve (fig. 2).

\section{Statistical Analyses}

All statistical analyses were performed in SAS statistical software (ver. 9.2; SAS Institute, Cary, NC). We first examined whether baseline CORT varied with year (proc GLM), and since we detected no year effects (see "Results"), we pooled data for subsequent analysis. We then analyzed effects of age and sex in a separate model (two-way ANOVA, proc GLM) since we had several birds where sex and age were unknown, and we did not want to exclude these in the subsequent model testing for effects of body mass or condition, Julian day, and time of capture. We then analyzed effects body mass, body condition (mass/tarsus), and time of day on baseline CORT (proc GLM).

Second, we analyzed variation in the stress response (change in CORT with time) using a mixed model with CORT as the dependent variable; year and time $(0,10,20,30 \mathrm{~min})$ as factors; mass, time of capture, and Julian day as covariates; and sample as a random factor to control for the repeated sampling of individuals. We repeated this analysis using body condition, rather than body mass, as a covariate. In both cases, there was a significant year $x$ time interaction so we subsequently ran models by year or time, with paired contrasts and Tukey-Kramer adjustment to test for significant differences among years or among each time period.

Finally, we examined sources of variation in the change in 


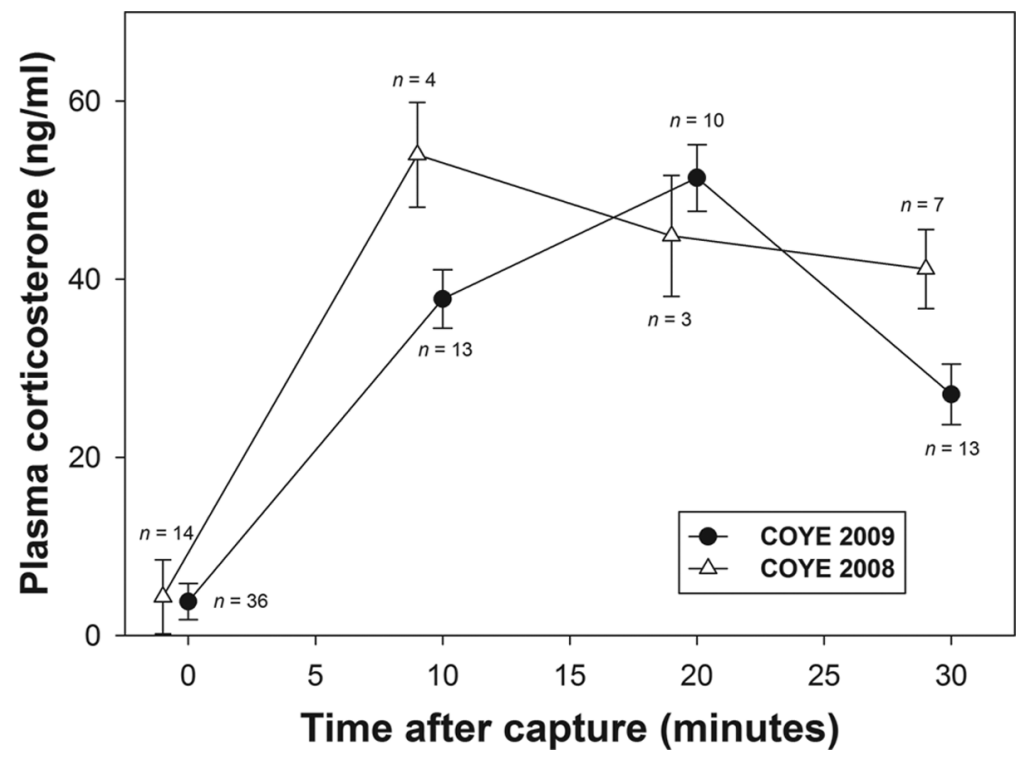

Figure 2. Stress-induced corticosterone (CORT) response curve. Changes in plasma CORT between 0 and 30 min in response to a standardized handling protocol. Individuals birds were sampled twice: at baseline ( $<3 \mathrm{~min}$ after capture) and again after 10, 20, or $30 \mathrm{~min}$. COYE $=$ common yellowthroat.

plasma CORT between specific time periods. To maximize statistical power, we calculated the change in plasma CORT between time periods where we had the largest sample size: between baseline and $10 \mathrm{~min}(n=12)$ and between baseline and $30 \min (n=19)$. We then analyzed effects of body mass, body condition (mass/tarsus), Julian day, and time of capture on change in CORT and maximum CORT (proc GLM) for each of these time intervals, and we report univariate correlations for significant variables.

\section{Results}

\section{Baseline CORT}

In 2009, three birds had high levels of baseline CORT (>18 ng/ $\mathrm{mL})$ compared with all other birds $(\leq 9 \mathrm{ng} / \mathrm{mL})$. However, two of these three individuals showed robust stress-induced increases in plasma CORT ( $>49 \mathrm{ng} / \mathrm{mL}$ ); therefore, we analyzed baseline CORT data including and excluding these birds. There was no difference in baseline CORT levels among years (including all birds: $2008=4.32 \pm 2.00 \mathrm{ng} / \mathrm{mL}, 2009=$ $4.30 \pm 0.97 \mathrm{ng} / \mathrm{mL} ; F_{1,37}=0.02, P>0.80$; excluding the three high-baseline birds: $2008=2.20 \pm 0.99 \mathrm{ng} / \mathrm{mL}, 2009=$ $2.36 \pm 0.50 \mathrm{ng} / \mathrm{mL} ; F_{1,34}=3.75, P=0.07$; table 1). Baseline CORT did not differ with sex $(P>0.85 ; n=9$ females, 16 males), age $(P>0.60$; although we caught and aged only $n=$ 3 after-hatch year birds, and $n=36$ hatch year birds), or sex $\times$ age $(P>0.75$, including all birds; excluding the three sexed high-baseline birds did not change these results). Baseline CORT was independent of body mass, body condition, Julian day, and time of capture either including or excluding the three high-baseline individuals (all $P>0.19$ ).

\section{Stress-Induced CORT}

The three individuals with high baseline CORT levels $(22.18$, 23.49 , and $18.19 \mathrm{ng} / \mathrm{mL}$ ) had stress-induced CORT levels after 10 or $30 \mathrm{~min}$ of $23.60,49.43$, and $84.07 \mathrm{ng} / \mathrm{mL}$; that is, two of these birds showed a robust stress response. We therefore included all birds in analysis of stress-induced CORT levels (table $1)$. In the overall model including all data from both years, there was a significant year $\times$ time interaction $\left(F_{3,64.7}=3.10\right.$, $P=0.033$ ) but no effect of body mass (or body condition), time of capture, or Julian day ( $P>0.19$ in all cases). Analyzing data for each year separately, we found a highly significant change in plasma CORT levels with time after capture in both $2008\left(F_{3,18}=12.70, P<0.001\right.$; fig. 2$)$ and $2009\left(F_{3,50}=89.2\right.$, $P<0.001$; fig. 2), with peak levels at $10 \mathrm{~min}$ in 2008 and at 20 min postcapture in 2009 (fig. 2). There was no effect of body mass (or body condition), time of capture, or Julian day in either year $(P>0.05$ in all cases). Post hoc analysis indicated that plasma CORT levels at 10, 20, and 30 min were all significantly higher than baseline levels $(P<0.01$ in all cases). There was no significant difference among 10-, 20-, or 30-min samples $(P>0.20)$ in 2008. However, in 2009 plasma CORT levels increased from 0 to $10 \mathrm{~min}(P<0.001)$ and again from 10 to $20 \mathrm{~min}(P<0.01)$ but then decreased between 20 and $30 \mathrm{~min}(P<0.001)$ postcapture. Paired contrasts by time interval showed that plasma CORT levels were higher in 2008 at $10 \mathrm{~min}(P<0.05)$ and $30 \mathrm{~min}(P<0.05)$ compared with 2009 (fig. 2).

Both stress-induced CORT and change in plasma CORT were independent of body mass, body condition, and time of capture at both 10 and $30 \mathrm{~min}$ ( $P>0.20$ in all cases), but there was a 
Table 1: Mean corticosterone values $(\mathrm{ng} / \mathrm{mL} \pm \mathrm{SE})$

\begin{tabular}{lcccc}
\hline Year & Baseline $(<3 \mathrm{~min})$ & $10 \mathrm{~min}$ & $20 \mathrm{~min}$ & $30 \mathrm{~min}$ \\
\hline 2008 & $4.32 \pm 2.00$ & $53.98 \pm 15.50$ & $44.86 \pm 6.24$ & $41.19 \pm 5.13$ \\
2009 & $4.30 \pm .97$ & $37.90 \pm 4.94$ & $50.77 \pm 3.86$ & $50.60 \pm 2.13$ \\
\hline
\end{tabular}

significant effect of Julian day for all measures of CORT (reduced model, $P<0.05$ in all cases). The change in CORT between 0 and $10 \mathrm{~min}$ and between 0 and $30 \mathrm{~min}$ was positively correlated with Julian day $\left(r_{12}=0.65, P<0.05\right.$, and $r_{18}=$ $0.48, P<0.05$, respectively; fig. $3 A, 3 B$ ). Similarly, stress-induced plasma CORT levels were positively correlated with Julian day at both 10 and $30 \mathrm{~min}\left(r_{12}=0.72, P<0.01\right.$, and $r_{18}=0.50$, $P<0.05$, respectively; fig. $3 C, 3 D)$.

\section{Discussion}

One of the main aims of this study was to test the MMH, which predicts that baseline CORT is elevated in migratory birds to facilitate hyperphagia and lipogenesis and that further elevation of CORT in response to an acute stressor is suppressed to protect skeletal muscle (Holberton et al. 1996, 2007, 2008; Holberton 1999; Long and Holberton 2004; Raja-aho et al. 2010). In conjunction with recent experimental work (Nilsson and Sandell 2009), our data appear to challenge these predictions: common yellowthroats captured during the migration period had low baseline plasma CORT levels at initial capture and then showed a robust stress response with a standardized handling stress protocol. We also found that maximum stress-induced CORT levels occurred only 10 or $20 \mathrm{~min}$ after capture and in one year were already declining by $30 \mathrm{~min}$ postcapture. The change in peak stress-induced levels from 2008 and 2009 suggests that the true peak may occur between 10 and $20 \mathrm{~min}$ postcapture (fig. 2). We found no strong evidence for annual variation in baseline CORT, and this was independent of body mass, date, or time of day. However, baseline CORT was statistically lower in females compared to males, but this could be explored further considering that some individuals were excluded from analysis. In contrast, there was some evidence for annual variation in the pattern of the stress response and for an effect of Julian day with the rate of increase in plasma CORT being higher later in the migration period.

Our study strongly suggests that common yellowthroats are characterized by low baseline CORT and a standard stress response during their active migration period (fig. 2). Interestingly, we also detected a significant increase in maximum stressinduced CORT throughout the migration period. Individual common yellowthroats had mean baseline CORT levels $<5 \mathrm{ng} /$ $\mathrm{mL}$ at initial capture, similar to baseline CORT values reported for other passerines (e.g., Gambel's white-crowned sparrows [Zonotrichia leucophrys gambelii], $3.78 \pm 0.44 \mathrm{ng} / \mathrm{mL}$; Romero and Wingfield 1999; American redstarts [Setophaga ruticilla], $<10 \mathrm{ng} / \mathrm{mL}$; Angelier et al. 2010) but far lower than baseline levels (30-40 ng/mL) reported for actively migrating hermit thrushes (Catharus guttatus; Holberton et al. 1996) and yellowrumped warblers (Dendroica coronata; Long and Holberton
2004). Our data are therefore consistent with Romero's (2002) suggestion that baseline CORT is low during fall migration. Furthermore, common yellowthroats showed a robust stress response following a standardized handling stress protocol. In contrast, in migrating yellow-rumped warblers CORT levels did not change significantly over a 60 -min sampling period with handling stress (Holberton et al. 1996), and in migrating hermit thrushes CORT only increased from 37 to $54 \mathrm{ng} / \mathrm{mL}$ (Long and Holberton 2004). Common yellowthroats have a life history similar to that of the yellow-rumped warblers studied in Holberton et al. (1996), but there might be several possible explanations for these contradictory results.

First, Long and Holberton (2004) describe their baseline sampling as being within $5 \mathrm{~min}$ of capture; however, more recent studies have suggested that baseline CORT must be obtained within 3 min of capture (e.g., Angelier et al. 2010). It is possible that baseline CORT increases significantly with this additional 2-min delay. Second, elevated baseline CORT might play a key regulatory role in initial development of migratory condition and especially in lean birds (Long and Holberton 2004; Holberton et al. 2007, 2008). The common yellowthroats we sampled had a fat score of 0 but were actively fattening (based on triglyceride analysis; Wagner 2012). Alternatively, Falsone et al. (2009) found that baseline CORT of night migrants was higher in birds caught out of nocturnal migration than in birds resting and foraging and suggested that a rise in circulating CORT may facilitate the heightened metabolic processes of active flight. Therefore, stopover duration and or/time between arrival at stopover sites and CORT sampling might affect measured baseline CORT levels.

We sampled birds during their active migration period ( $\mathrm{Au}-$ gust 1-September 30; fig. 1). However, since common yellowthroats are also locally occurring breeders at our study, site we may have sampled some premigratory individuals. Yet, we found a consistently significant stress response throughout the sampling period; that is to say we were able to detect a change in CORT between baseline and subsequent sampling periods in all individuals that were sampled twice. As such, we do not believe these issues confound our results, since previous research suggests that individuals undergoing prebasic molt have a suppressed stress response and low baseline CORT level (Breuner et al. 1999; Romero and Remage-Healey 2000; Romero 2002).

Another important finding in our study, relevant to comparison among different studies, was that peak plasma CORT concentration occurs closer to 10 or $20 \mathrm{~min}$ after initial onset of a stressor in this small-bodied migratory passerine. This is less than the standard 30-min poststress sampling interval that is widely used in other studies, as has been historically assumed 

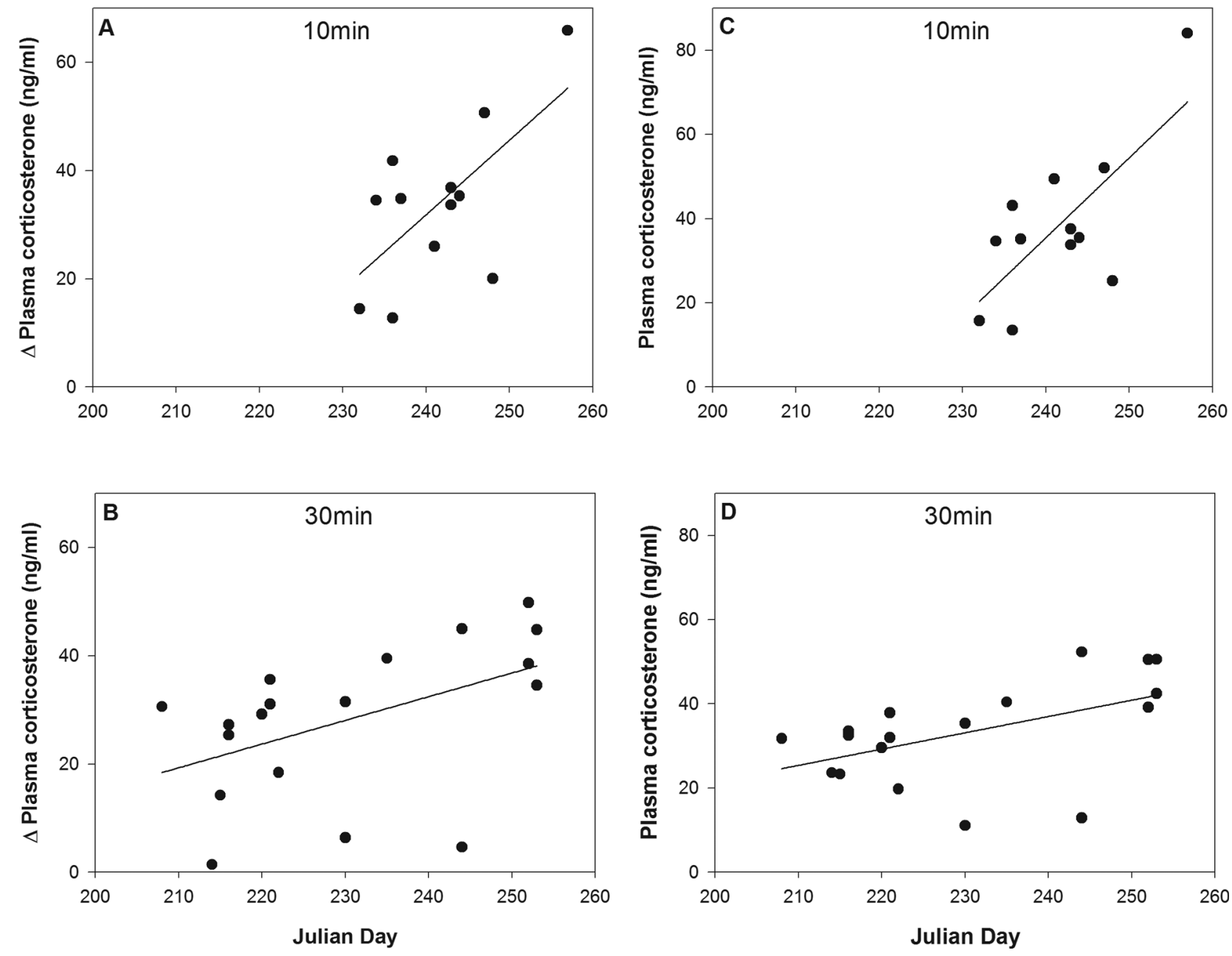

Figure 3. Change in stress-induced corticosterone (CORT). Relationship between Julian day and change in stress-induced CORT between 0 and $10 \mathrm{~min}(A)$ and between 0 and $30 \mathrm{~min}(B)$ or maximum stress-induced CORT at $10 \mathrm{~min}(C)$ or 30 min $(D)$ postcapture. Data for 2008 and 2009 are pooled.

and as has been used as the standard when comparing patterns of annual variation in species (Wingfield et al. 1995; Romero et al. 1997; Holberton 1999; Landys et al. 2004) or variation of individuals during a single sampling period (Holberton and Able 2000; Cockrem et al. 2009; Done et al. 2011). Indeed, our data suggest that plasma CORT levels are already declining after $30 \mathrm{~min}$ of handling for these small passerines. These results are consistent with a study investigating repeatability of stressinduced CORT measurements in great tits (Parus major; Cockrem and Silverin 2002) and are worth reemphasizing. Many studies may therefore be underestimating or missing the peak of the stress response, and this might confound comparison among different studies. Our study suggests that the use of CORT as a monitoring tool to examine how the environment influences individuals requires a species-specific understanding of the stress-induced CORT response curve.

We found only weak evidence for an effect of sex on baseline CORT: females had lower levels than males when we excluded high-baseline individuals. Marra and Holberton (1998) and
O'Reilly and Wingfield (2003) found no effect of sex on baseline CORT or the stress response in migratory passerines or premigratory shorebirds, respectively. However, other studies have previously reported differences between male and female baseline CORT level (Meddle et al. 2003), as well as differences in stress response (O'Reilly and Wingfield 2003; Jenni-Eiermann et al. 2008). However, these studies focused primarily on the breeding season, where sex differences are thought to be related to differential parental investment. Further study is required to determine whether there are sex differences in baseline CORT that need to be controlled for. We also found no relationship between baseline or stress-induced CORT and body mass in our study. Holberton and Long (2004) similarly found no relationship between the stress response and energetic condition estimated from a regression of mass on wing chord in migrating hermit thrushes. However, other studies have reported a relationship between CORT and condition of migrants (Falsone et al. 2009; Raja-aho et al. 2010). Additionally, there is a frequently reported relationship between poor condition and 
higher CORT in nonmigrants (Bonier et al. 2009a, 2009b). This lack of consensus in the literature concerning how CORT relates to body condition during different life-history stages demands further investigation, as this relationship is important for population monitoring.

In the context of using CORT as a monitoring tool for migration studies, we did detect an effect of year and Julian day on stress-induced CORT levels in our study. Especially at the 10-min interval, we found a significant increase in CORT concentration with respect to Julian day. This pattern of annual variation in physiological traits related to energetic management is consistent with previous studies (Holberton et al. 1996; Love et al. 2004; Raja-aho et al. 2010). This relationship is thought to be due to subtly changing environmental conditions throughout the migratory season (Holberton and Able 2000; Heise and Moore 2003). The difference in average stressinduced CORT levels between years is potentially supportive of its use as an environmental monitoring tool, given that there is potentially great annual variability in habitat quality in anthropogenically impacted sites such as Revelstoke Reach. Interestingly, we detected an increase in stress-induced levels as water levels decreased at this stopover site (figs. 1, 3). Counter to initial hypotheses, this could be due to desiccation of the riparian habitat and reduced food availability associated with falling water levels. However, given other changing environmental conditions, this is potentially confounded and requires further study. If a pattern of migratory passerine baseline or stress-induced CORT levels can be developed and shown to be consistent among passerine species, then plasma CORT sampling could be a viable and potentially powerful technique for assessing various conservation or environmental assessment efforts (Romero and Wikelski 2002; Wikelski et al. 2002; Walker et al. 2005; Cooke and O'Connor 2010). The ability to evaluate restoration programs immediately upon completion or while under way is an area where demographic sampling is limited and could be a particularly useful venue in which to use physiology to evaluate project success. Conservation physiology using CORT is a very attractive concept and has been shown to be useful in a number of different studies (Wikelski and Cooke 2006). However, for results to be interpreted, using CORT as a monitoring tool requires a specific understanding of how sex, different life-history stages, and species-specific timing of stressinduced response may affect CORT (Madliger and Love 2014).

\section{Acknowledgments}

We would like to thank BC Hydro; Cooper, Beauchesne, and Associates; the Natural Sciences and Engineering Research Council of Canada; and the Canadian Wildlife Service for support and funding. We would also like to thank Michal Pavlik, Russell Cannings, Jeannine Randall, Rudy Badia, Lucie Parker, Paul Levesque, Margaret Eng, Marc Travers, and Janice Jarvis for help in data collection and useful comments.

\section{Literature Cited}

Angelier F., C.M. Tonra, R.L. Holberton, and P.P. Marra. 2010. How to capture wild passerine species to study baseline corticosterone levels. J Ornithol 151:415-422.

Baker A.J., P.M. Gonzalez, T. Piersma, L.J. Niles, I.D.S. do Nascimento, P.W. Atkinson, N.A. Clark, C.D.T. Minton, M.K. Peck, and G. Aarts. 2004. Rapid population decline in red knots: fitness consequences of decreased refuelling rates and late arrival in Delaware Bay. Proc R Soc B 271:875-882.

Bonier F., P.R. Martin, I.T. Moore, and J.C. Wingfield. $2009 a$. Do baseline glucocorticoids predict fitness? Trends Ecol Evol 24:634-642.

Bonier F., I.T. Moore, P.R. Martin, and R.J. Robertson. $2009 b$. The relationship between fitness and baseline glucocorticoids in a passerine bird. Gen Comp Endocrinol 163:208-213.

Bowlin M.S., I.A. Bisson, J. Shamoun-Baranes, J.D. Reichard, N. Sapir, P.P. Marra, T.H. Kunz, et al. 2010. Grand challenges in migration biology. Integr Comp Biol 50:261-279.

Breuner C.W. and M. Orchinik. 2002. Plasma binding proteins as mediators of corticosteroid action in vertebrates. J Endocrinol 175:99-112.

Breuner C.W., J.C. Wingfield, and L.M. Romero. 1999. Diel rhythms of basal and stress-induced corticosterone in a wild, seasonal vertebrate, Gambel's white-crowned sparrow. J Exp Zool 284:334-342.

Cockrem J.F., D.P. Barrett, E.J. Candy, and M.A. Potter. 2009. Corticosterone responses in birds: individual variation and repeatability in Adelie penguins (Pygoscelis adeliae) and other species, and the use of power analysis to determine sample sizes. Gen Comp Endocrinol 163:158-168.

Cockrem J.F. and B. Silverin. 2002. Variation within and between birds in corticosterone responses of great tits (Parus major). Gen Comp Endocrinol 125:197-206.

Cooke S.J. and C.M. O'Connor. 2010. Making conservation physiology relevant to policy makers and conservation practitioners. Conserv Lett 3:159-166.

Cornelius J.M., T. Boswell, S. Jenni-Eiermann, C.W. Breuner, and M. Ramenofsky. 2013. Contributions of endocrinology to the migration life history of birds. Gen Comp Endocrinol 190:47-60.

Done T., E.A. Gow, and B.J.M. Stutchbury. 2011. Corticosterone stress response and plasma metabolite levels during breeding and molt in a free-living migratory songbird, the wood thrush (Hylocichla mustelina). Gen Comp Endocrinol 171:176-182.

Faaborg J., R.T. Holmes, A.D. Anders, K.L. Bildstein, K.M. Dugger, S.A. Gauthreaux, P. Heglund, et al. 2010a. Conserving migratory land birds in the New World: do we know enough? Ecol Appl 20:398-418.

. 2010b. Recent advances in understanding migration systems of New World land birds. Ecol Monogr 80:3-48.

Falsone K., S. Jenni-Eiermann, and L. Jenni. 2009. Corticosterone in migrating songbirds during endurance flight. Horm Behav 56:548-556.

Green D.J., K.B. Loukes, M.W. Pennell, J. Jarvis, and W.E. 
Easton. 2011. Reservoir water levels do not influence daily mass gain of warblers at a riparian stopover site. J Field Ornithol 82:11-24.

Harvey S., J.G. Phillips, A. Rees, and T.R. Hall. 1984. Stress and adrenal function. J Exp Zool 232:633-645.

Heise C.D. and F.R. Moore. 2003. Age-related differences in foraging efficiency, molt, and fat deposition of gray catbirds prior to autumn migration. Condor 105:496-504.

Holberton R.L. 1999. Changes in patterns of corticosterone secretion concurrent with migratory fattening in a Neotropical migratory bird. Gen Comp Endocrinol 116:49-58.

Holberton R.L. and K.P. Able. 2000. Differential migration and an endocrine response to stress in wintering dark-eyed juncos (Junco hyemalis). Proc R Soc B 267:1889-1896.

Holberton R.L., T. Boswell, and M.J. Hunter. 2008. Circulating prolactin and corticosterone concentrations during the development of migratory condition in the dark-eyed junco, Junco hyemalis. Gen Comp Endocrinol 155:641-649.

Holberton R.L., J.D. Parrish, and J.C. Wingfield. 1996. Modulation of the adrenocortical stress response in Neotropical migrants during autumn migration. Auk 113:558-564.

Holberton R.L., C.M. Wilson, M.J. Hunter, W.B. Cash, and C.G. Sims. 2007. The role of corticosterone in supporting migratory lipogenesis in the dark-eyed junco, Junco hyemalis: a model for central and peripheral regulation. Physiol Biochem Zool 80:125-137.

Jenni-Eiermann S., E. Glaus, M. Gruebler, H. Schwabl, and L. Jenni. 2008. Glucocorticoid response to food availability in breeding barn swallows (Hirundo rustica). Gen Comp Endocrinol 155:558-565.

Kitaysky A.S., E.V. Kitaiskaia, J.C. Wingfield, and J.F. Piatt. 2001. Dietary restriction causes chronic elevation of corticosterone and enhances stress response in red-legged kittiwake chicks. J Comp Physiol B 171:701-709.

Kitaysky A.S., J.F. Piatt, and J.C. Wingfield. 2007. Stress hormones link food availability and population processes in seabirds. Mar Ecol Progr Ser 352:245-258.

Kitaysky A.S., J.F. Piatt, J.C. Wingfield, and M. Romano. 1999. The adrenocortical stress response of black-legged kittiwake chicks in relation to dietary restrictions. J Comp Physiol B 169:303-310.

Kraan C., J.A. van Gils, B. Spaans, A. Dekinga, and T. Piersma. 2010. Why Afro-Siberian red knots Calidris canutus canutus have stopped staging in the western Dutch Wadden Sea during southward migration. Ardea 98:155-160.

Landys M.T.M., J.C. Wingfield, and M. Ramenofsky. 2004. Plasma corticosterone increases during migratory restlessness in the captive white-crowned sparrow Zonotrichia leucophrys gambelli. Horm Behav 46:574-581.

Lobato E., J. Moreno, S. Merino, J. Morales, G. Tomas, J. Martinez, R.A. Vasquez, A. Kuchar, E. Mostl, and J.L. Osorno. 2010. Arrival date and territorial behavior are associated with corticosterone metabolite levels in a migratory bird. J Ornithol 151:587-597.

Long J.A. and R.L. Holberton. 2004. Corticosterone secretion, energetic condition, and a test of the migration modulation hypothesis in the hermit thrush (Catharus guttatus), a shortdistance migrant. Auk 121:1094-1102.

Love O.P., C.W. Breuner, F. Vezina, and T.D. Williams. 2004. Mediation of a corticosterone-induced reproductive conflict. Horm Behav 46:59-65.

Love O.P., E.H. Chin, K.E. Wynne-Edwards, and T.D. Williams. 2005. Stress hormones: a link between maternal condition and sex-biased reproductive investment. Am Nat 166:751766.

Love O.P. and T.D. Williams. 2008. Plasticity in the adrenocortical response of a free-living vertebrate: the role of preand post-natal developmental stress. Horm Behav 54:496505.

Madliger C.L. and O.P. Love. 2014. The need for a predictive, context-dependent approach to the application of stress hormones in conservation. Conserv Biol 28:283-287.

Marra P.P. and R.L. Holberton. 1998. Corticosterone levels as indicators of habitat quality: effects of habitat segregation in a migratory bird during the non-breeding season. Oecologia 116:284-292.

Meddle S.L., N.T. Owen-Ashley, M.I. Richardson, and J.C. Wingfield. 2003. Modulation of the hypothalamic-pituitaryadrenal axis of an Arctic-breeding polygynandrous songbird, the Smith's longspur, Calcarius pictus. Proc R Soc B 270: 1849-1856.

Nilsson A.L.K. and M.I. Sandell. 2009. Stress hormone dynamics: an adaptation to migration? Biol Lett 5:480-483.

O'Reilly K.M. and J.C. Wingfield. 2003. Seasonal, age, and sex differences in weight, fat reserves, and plasma corticosterone in western sandpipers. Condor 105:13-26.

Pasinelli G., M. Schaub, G. Hafliger, M. Frey, H. Jakober, M. Muller, W. Stauber, P. Tryjanowski, J.L. Zollinger, and L. Jenni. 2011. Impact of density and environmental factors on population fluctuations in a migratory passerine. J Anim Ecol 80:225-234.

Pyle P. 1997. Identification guide to North American birds. I. Columbidae to Ploceidae. Slate Creek, Bolina, CA.

Raja-aho S., P. Suorsa, M. Vainio, M. Nikinmaa, E. Lehikoinen, and T. Eeva. 2010. Body condition is associated with adrenocortical response in the barn swallow (Hirundo rustica L.) during early stages of autumn migration. Oecologia 163:323332.

Ramenofsky M. and J.C. Wingfield. 2007. Regulation of migration. Bioscience 57:135-143.

Romero L.M. 2002. Seasonal changes in plasma glucocorticoid concentrations in free-living vertebrates. Gen Comp Endocrinol 128:1-24.

2004. Physiological stress in ecology: lessons from biomedical research. Trends Ecol Evol 19:249-255.

Romero L.M., M. Ramenofsky, and J.C. Wingfield. 1997. Season and migration alters the corticosterone response to capture and handling in an Arctic migrant, the white-crowned sparrow (Zonotrichia leucophrys gambelii). Comp Biochem Physiol C 116:171-177.

Romero L.M. and L. Remage-Healey. 2000. Daily and seasonal 
variation in response to stress in captive starlings (Sturnus vulgaris): corticosterone. Gen Comp Endocrinol 119:52-59.

Romero L.M. and J.M. Reed. 2005. Collecting baseline corticosterone samples in the field: is under $3 \mathrm{~min}$ good enough? Comp Biochem Physiol A 140:73-79.

Romero L.M. and M. Wikelski. 2002. Severe effects of low-level oil contamination on wildlife predicted by the corticosterone stress response: preliminary data and a research agenda. Spill Sci Technol Bull 7:309-313.

Romero L.M. and J.C. Wingfield. 1999. Alterations in hypothalamic-pituitary-adrenal function associated with captivity in Gambel's white-crowned sparrows (Zonotrichia leucophrys gambelii). Comp Biochem Physiol B 122:13-20.

Sauer J.R., J.E. Hines, J.E. Fallon, K.L. Pardieck, D.J. Ziolkowski Jr., and W.A. Link. 2011. The North American Breeding Bird Survey: results and analysis 1966-2010. Version 12.07.2011. USGS Patuxent Wildlife Research Center, Laurel, MD.

Seewagen C.L., E.J. Slayton, and C.G. Guglielmo. 2010. Passerine migrant stopover duration and spatial behaviour at an urban stopover site. Acta Oecol 36:484-492.

Sheehy J., C.M. Taylor, K.S. McCann, and D.R. Norris. 2010. Optimal conservation planning for migratory animals: integrating demographic information across seasons. Conserv Lett 3:192-202.

Suorsa P., E. Huhta, A. Nikula, M. Nikinmaa, A. Jantti, H. Helle, and H. Hakkarainen. 2003. Forest management is associated with physiological stress in an old-growth forest passerine. Proc R Soc B 270:963-969.

Wagner D.N. 2012. Impact of hydroelectric operations on the physiology of songbirds during fall migration. Department of Biological Sciences, Simon Fraser University, Burnaby, British Columbia.
Walker B.G., P.D. Boersma, and J.C. Wingfield. 2005. Field endocrinology and conservation biology. Integr Comp Biol 45:12-18.

Wasser S.K. and K.E. Hunt. 2005. Noninvasive measures of reproductive function and disturbance in the barred owl, great horned owl, and northern spotted owl. Pp. 109-137 in U. Bauchinger, W. Goymann, and S. JenniEiermann, eds. Bird hormones and bird migrations: analyzing hormones in droppings and egg yolks and assessing adaptations in longdistance migration. New York Academy of Sciences, New York.

Wikelski M. and S.J. Cooke. 2006. Conservation physiology. Trends Ecol Evol 21:38-46.

Wikelski M., V. Wong, B. Chevalier, N. Rattenborg, and H.L. Snell. 2002. Marine iguanas die from trace oil pollution. Nature 417:607-608.

Williams T.D., N. Warnock, J.Y. Takekawa, and M.A. Bishop. 2007. Flyway-scale variation in plasma triglyceride levels as an index of refueling rate in spring-migrating western sandpipers (Calidris mauri). Auk 124:886-897.

Wingfield J.C., K.M. O’Reilly, and L.B. Astheimer. 1995. Modulation of the adrenocortical responses to acute stress in Arctic birds: a possible ecological basis. Am Zool 35:285294.

Wingfield J.C., J.P. Smith, and D.S. Farner. 1982. Endocrine responses of white-crowned sparrows to environmental stress. Condor 84:399-409.

Wingfield J.C., C.M. Vleck, and M.C. Moore. 1992. Seasonal changes of the adrenocortical response to stress in birds of the Sonoran Desert. J Exp Zool 264:419-428. 
Copyright of Physiological \& Biochemical Zoology is the property of University of Chicago Press and its content may not be copied or emailed to multiple sites or posted to a listserv without the copyright holder's express written permission. However, users may print, download, or email articles for individual use. 